IRA-International Journal of Education \& Multidisciplinary Studies

ISSN 2455-2526; Vol.15, Issue 05 (Oct.-Dec. 2019)

Pg. no. 205-208.

Institute of Research Advances

http://research-advances.org/index.php/IJEMS

QUARTERLY

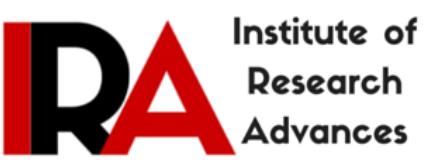

\title{
A Cultural Perspective on the English Translation of Nezha
}

Xiaoyan Li

School of Foreign Studies, Yangtze University, Hubei, 434023 PRC China

Type of Work: Peer-Reviewed

DOl: http://dx.doi.org/10.21013/jems.v15.n5.p7

\section{How to cite this paper:}

Li., X. (2019). A Cultural Perspective on the English Translation of Nezha. IRA International Journal of Education and Multidisciplinary Studies (ISSN 2455-2526), 15(5), 205-208.doi: http://dx.doi.org/10.21013/jems.v15.n5.p7

(C) Institute of Research Advances.

This work is licensed under a Creative Commons Attribution-Non Commercial 4.0 International License subject to a proper citation to the publication source of the work.

Disclaimer: The scholarly papers as reviewed and published by the Institute of Research Advances (IRA) are the views and opinions of their respective authors and are not the views or opinions of the IRA. The IRA disclaims of any harm or loss caused due to the published content to any party.

Institute of Research Advances is an institutional publisher member of Publishers International Linking Association Inc. (PILA-CrossRef), USA. The institute is an institutional signatory to the Budapest Open Access Initiative, Hungary advocating the open-access of scientific and scholarly knowledge. The Institute is a registered content provider under Open Access Initiative Protocol for Metadata Harvesting (OAI-PMH).

The journal is indexed \& included in WorldCat Discovery Service (USA), CrossRef Metadata Search (USA), WorldCat (USA), OCLC (USA), Open J-Gate (India), EZB (Germany) Scilit (Switzerland), Airiti (China), Bielefeld Academic Search Engine (BASE) of Bielefeld University, Germany, PKP Index of Simon Fraser University, Canada. 


\section{ABSTRACT}

Achieving a tremendous box office success in China, Na Zha is a mythical movie with Chinese characteristics, showing the social culture of China, analyzing the current ideological situation of the modern Chinese people, but it flopped in the American market. This paper analyses the gains and losses in the translation of the film Nezha from the perspective of culture.

Keywords: Nezha, culture, translation

\section{Brief introduction of Nezha}

The movie Nezha /Nezha: Birth of the Demon Child, released in July 2019 in China, is currently ranked 8.6 in Douban (American Rotten Tomato) and the total box office is over 5 billion yuan. Although Nezha is a "devil boy", he has to go against his fate and fight heroically to be himself. Chinese people see similarities in the life of Nezha and their own: they try to change their lives against all odds, control life in their own hands and strive for their dreams. The animated film hit a new height in China, was also released overseas, but flopped. To some extent, this is due to cultural differences and translation. The translation is a code switch in culture and it does not occur in a vacuum (Venuti, 2004). Translation activities are always constrained by the author's background and preferences of the target readers or audience. Different cultures make translation difficult, and translation activities are always carried out in a certain space-time context. Only by placing translation activities in the specific context can we make translation proper.

\section{Cultural Background and Translation of Nezha}

\subsection{Cultural Background}

Chinese President Xi Jinping put forward "to tell the story of China well, illustrate the spirit of China and show the Chinese style, so that foreign people can deepen their understanding of China, enhance their understanding of China and ... appreciating Chinese works" at the Forum on Literary and Artistic Work, held in October 2014. How to tell the story of China well? The premise is to have a clear understanding of one's own culture. In the eyes of the Chinese, rebellious and unruly, courageous in the pursuit of self-fulfilment, and self-centred, represent the typical Western character traits, which are most vividly reflected in Nezha.

Facing the increasingly complex and pluralistic global cultural environment, the concept of "cultural consciousness" proposed by Chinese Sociologist Fei (2007) emphasizes the "self-knowledge" of one's home culture. Neither agrees with "recovery" nor advocates "wholesale westernization" or "holistic".

\subsection{Translation in Nezha}

The practice of translation is inseparable from language awareness and strategies. In a word, the cultural self-knowledge and the cultural self-consciousness of embracing others are the real cultural confidence. Such kind of translation works can stand the test of history and be competitive in the new era. Nezha is a household name in China. Nezha's character and image have been deeply rooted in the hearts of Chinese people through a series of works. Nezha hit the hearts of the contemporary Chinese people as not to accept fate. But not so abroad.

\subsubsection{Movie Title Translation}

Statistics show that 80 per cent of film names are translated literally in China, and the remaining 20 per cent are completely "unconventional". For example, The Others, Cast Away, Casablanca, Hamlet, Ghost, Pretty Woman, Charle's Angels, such titles can hardly be translated back into English. Therefore, 
the current situation of film title translation has always been questioned by many people in China's translation industry, who believe that the current film title translation market is too chaotic and there are few good translations. Nezha /Nezha: Birth of the Demon Child follows the principle recognized by the Chinese translation circle, which is regarded as a good version by Chinese netizens.

\subsubsection{Movie Line Translation}

Throughout the translation history of more than one hundred years in China, the common foundation of both the "faithfulness, expressiveness and elegance" advocated by the outstanding Chinese translator Yan fu, and the "prefer faithfulness to elegance" by the great Chinese writer Lu Xun, is "faithfulness to the original text".

Because of the mythological and legendary physique, Nezha has a lot of mythological terms, many of which are rooted in Chinese tradition. How can these terms be understood by foreign audiences without any relevant background knowledge? The official translation of the lines in the film is not good, and there is a lack of consideration for cultural differences. Compared with The Three-body Problem, it is too "playful".

Many lines resonate with everyone, but their translation is not satisfactory. "I'm the master of my own fate"; "If fate isn't fair, fight it till the end", "I'm the one who decides, if I'm immortal or demon", "forget your fate or screw your fate", "Not to accept, is Nezha's fate", "Forget what other people think, you are the only one who controls what you become". Although these translations are accurate, the original Chinese strength and rebellion get lost. The English version also lacks a certain rhythm. It only achieves faithfulness, which is also acceptable but lacks elegance. There are also many cultural words with Chinese characteristics in the film, and the translation is ridiculed by many Chinese audiences. For example:

\section{Qiankun Hoop}

It is difficult to find a suitable English coat for the word "Qiankun Quan”, which has long appeared in Chinese mythology. There is heated discussion over the English version and there is a suggestion that it should be put in Pinyin “Qiankun Quan” instead of Qiankun Hoop.

Be quick to obey my command!

When he uses his weapon, Qiankun Hoop, Nezha will call out a spell, " Be quick to obey my command!". This sentence first appeared in the official documents of the Han Dynasty in ancient China, indicating that the situation is in a critical moment and that everything should be done as ordered in the official documents. Later, it became a Taoist term to ask the gods to enforce their decrees quickly. You can often hear this sentence in the movie and TV operas like The Graver Robbers' Chronicles and The Legend of Deification, which are very popular with Chinese young people. The translated version which was pointed out as simple and effective by People's Daily is as follows: fast fast biu biu. Although this translation does not obey any translation rules, it seems to be very suitable for the character Taiyi Zhenren, who is seen as cute by some, loves to drink, sleep and fat. In the magical world of Harry Potter, the spell is usually one or two words, like Petrificus Totalus and Expelliarmus. Even the whole sentences of spells, like the one that resurrected Voldemort, "the bones of your father, not intended to be given, will regenerate your son... Bone of father, unknowingly given, you will renew your son...... ", also has certain rhythm. Be quick to obey my command is not like a spell. "Go go is must", "gee gee rule in", "fast fast biu biu" are both funny and sound more like spells.

Demon Pill

Lingzhu and Mowan are extracted from the mixed beads of heaven and earth energy. They are 
reincarnated as human beings, while Mowan, (Demon pill) will produce the devil king, which is a disaster to the world. Demon pill is a kind of metaphysical product which gathers the spirit and evil spirit of heaven and earth. It sounds strange to translate into pill. However, in The Matrix, blue pill \& red pill represents two opposite situations of reality and illusion. It seems that foreign audiences can accept the concept of the opposite of spiritual pearl and magic pill.

Heaven Made Curse

In the magic world of Harry Potter, the word used in the fatal spell is curse, Avada Kedavra is a killing curse, small trick of magic is charm, Accio is defined as a charm that allows the caster to summon an object. Tianjie Zhou is to cause the lightening and thunder to strike Nezha to death. Translated into Heaven made curse may cause misunderstanding of the cultural connotation.

Ken Liu once said that he did not agree with the proposition that the translation should read like the original text in English. He (2014) transliterated some Chinese cultural items and did not add annotations in Three-body Problem. For example, he used dadao, mantou, tun, kang, qipao, educated youth, big-character poster, Five Black Categories, cowshed, Awakening of Insects, Major Heat, Cold Dew and Winter Solstice etc. Such a translation brings English readers closer to the source language and culture and brings them fresh reading experience.

\section{Conclusion}

American films introduce their own culture and values to the world. Hollywood, driven by profit rather than ideological marketing, is the best marketer of the American dream. Demonstrating the mainstream values of the United States, it is the most influential world stage to show American ideology to the world. Therefore, in the context of globalization, cross-cultural phenomena related to translation should be studied, and the characteristics of Chinese and western cultures should be recognized through rational analysis. Chinese culture and social reality can also be conveyed through films like Raise The Red Lantern, Crouching Tiger, Hidden Dragon, just like Hollywood movies Forrest Gump, Saving Private Ryan and Star Wars. The viewpoint Fei (2007) proposed, Cheng \& Zhang (2015) emphasized that every beauty is beautiful. Let the cultures of the world be beautiful in their own way. People can appreciate the beauty of different countries.

\section{References}

[1] Cheng Z \& Zhang Z. The Enlightenment of Fei Xiaotong's Thought of "Cultural Consciousness" to the English Translation of Classics [J]. Chinese Science and Technology Translation, 2015, 28 (1).

[2] Fei Xiaotong. On Culture and Cultural Consciousness. Beijing: Qunyan Press, 2007.

[3] Ken, L. The Three-Body Problem. New York: Tor Books, 2014a.

[4] Venuti, L. The Scandals of Translation. London and New York: Routledge, 1998.

[5] Xie Tianzhen. The cultural turn of translation studies: the comparative literary significance of cultural turn in translation studies [J]. Comparative Literature in China, 2006:1-14. 